\title{
Sintaxe de línguas particulares e sintaxe comparativa
}

\author{
Denilda Moura \\ Doutora em Linguística, pela Universidade \\ de Paris 8, professora do Programa de \\ Pós-Graduação em Letras e Linguística da \\ Universidade Federal de Alagoas.
}

Resumo: A análise da variação intralinguística tem merecido a atenção de estudiosos na busca de explicações satisfatórias para vários fenômenos linguísticos que ocorrem no interior de uma língua. Tendo em vista a ênfase a esses estudos, no que concerne à sintaxe gerativa, a partir de Princípios e Parâmetros, objetivamos realizar uma discussão sobre a questão da variação linguística nessa perspectiva teórica. E, de acordo com Kayne (2000), uma nova faceta da teoria sintática é a sintaxe comparativa, e enfatiza a importância dos estudos comparativos sobre a sintaxe das línguas e dialetos, como uma fonte de investigação bastante promissora para fornecer uma ampla compreensão da fixação de parâmetros nessas línguas e dialetos. É com base nessas perspectivas teóricas que pretendemos discutir a questão da sintaxe de línguas particulares e da sintaxe comparativa.

Palavras-chave: sintaxe; línguas particulares; sintaxe comparativa
Résumé: L'analyse de la variation intra-linguistique a mérité l'attention des studieux dans la recherche d'explication satisfaisante pour plusieurs phénomènes linguistiques qui arrivent l'antérieur d'une langue. Etant donné l'emphase à se études, en ce qui concerne la syntaxe générative, à partir des Principes et Paramètres, nous avons comme but réaliser une discussion sur la variation linguistique dans cette perspective théorique. Et, selon Kayne (2000), une nouvelle facette de la théorie syntaxique c'est la syntaxe comparative, et donne emphase sur l'importance des études comparatives sur la syntaxe des langues et des dialects, comme une source d'investigation assez importante pour fournir une ample compréhension sur la fixation des paramètres des se langues et dialects. Crist à la base de se perspectives théoriques que nous souhaitons discuter la question de la syntaxe des langues particulières et de la syntaxe comparative.

Mots-clé: syntaxe; langues particulières; syntaxe comparative 

Nos estudos sintáticos de línguas particulares, a análise da variação intralinguística tem merecido a atenção de estudiosos na busca de explicações satisfatórias para vários fenômenos linguísticos que ocorrem no interior de uma língua, sincrônica e/ou diacronicamente.

Para o gerativismo, a gramática universal é considerada uma teoria abstrata das propriedades linguísticas predeterminadas pela estrutura intrínseca do espírito humano/cérebro. Pode-se conceituar a gramática universal como uma função complexa, com um certo número de variáveis independentes, ou parâmetros. Os princípios caracterizam o espaço limitado à variação possível, e aprender uma língua quer dizer, nesse quadro conceitual, fixar os parâmetros à base da experiência, e derivar, assim, uma instanciação da gramática universal, a gramática de uma língua particular, cf. Rizzi (1988, p. 9).

Nesse quadro teórico, as ferramentas conceituais da gramática gerativa evoluíram muito nos últimos anos, mas o seu programa de investigação - fornecer uma descrição argumentada e rigorosa às duas questões seguintes permanece invariante:

a) como caracterizar o saber linguístico de falantes adultos de sua língua interna LI)?

b) como LI se desenvolve nos falantes?

Através do estudo detalhado e minucioso de (fragmentos isolados de) línguas internas particulares, sempre se tratou de desenvolver um modelo - um conjunto de regras e de princípios explícitos permitindo produzir os enunciados e suas descrições estruturais (DS), enfim, uma gramática gerativa da língua interna dos falantes e da faculdade de linguagem que a torna possível, cf. Pollock (1998, p. 199-200).

Pollock explicita, ainda, as propriedades desse modelo: 
1. Ele deve ser suficientemente flexível para dar conta das diferenças entre as LI de João, Maria, Pedro, etc. Mas ele deve também ser bastante restritivo para dar conta de sua aquisição natural, sem uma verdadeira aprendizagem;

2. Sobre o aspecto de LI: as estruturas, as operações sintáticas e as restrições sintáticas que as regem, podem ser resumidas como as propriedades salientes do modelo:

a) Ele é representacional

Dominar uma língua é poder construir um conjunto infinito de representações geométricas binárias a partir dos termos do léxico mental;

b) Ele é computacional

Dominar uma língua é poder efetuar computações ótimas sobre essas representações que satisfaçam às restrições de interface que pesem sobre a faculdade de linguagem.

Já que as representações de todas as línguas resultam da operação de computações, de forma universal, a diversidade evidente das línguas (internas) não pode provir, nesse modelo, da existência de construções ou regras específicas. Assim, o modelo minimalista rompe não somente com as análises da gramática clássica, mas também com os modelos padrão e padrão alargado da gramática gerativa.

Mas, como sabemos, a considerável diversidade linguística é atribuída ao fato de as computações universais poderem ser furtivas ou visíveis, e essa distinção é muitas vezes, talvez sempre, a consequência de diferenças entre línguas, ou construções de uma mesma língua, referentes à riqueza ou à pobreza morfológica das marcas funcionais, por exemplo às de caso, gênero, número e pessoa. 
Pollock destaca, ainda, que resultados precoces devidos a Rizzi (1978) sobre a questão de saber "que constituintes sintáticos contam como domínios cíclicos" sugeriram que as línguas e construções de uma mesma língua podem variar, em limites bastante estreitos sobre esse ponto. Para ele, o artigo de RIZZI foi o primeiro trabalho em gramática gerativa a propor uma articulação entre a invariância e a diversidade: a FL fornece princípios que regem as computações de todas as línguas, mas deixa no interior desses princípios um espaço de variação, um parâmetro, no qual as diferentes línguas (internas) podem fazer uma escolha, cf. (idem, p.105). ${ }^{1}$

Essa nova perspectiva conduz a trabalhos de sintaxe comparada produtivos no final dos anos 1970, e provoca nos anos 1980 uma verdadeira explosão de trabalhos comparativos sobre o conjunto das línguas indo-européias e seus dialetos, e sobre numerosas línguas africanas, ameríndias, semíticas e do extremo oriente. ${ }^{2}$

Rizzi (1988) apresenta uma Teoria da Sintaxe Comparativa, com base na gramática gerativa chomskyana. Para ele, a ideia de comparar línguas não é nova. No século XIX, a gramática comparativa obteve muito sucesso estabelecendo relações de origem e de parentesco entre as línguas à base de considerações comparativas, e vários enfoques comparativos para a tipologia das línguas obtiveram muito sucesso nesse século. Nos últimos dez anos, o modelo comparativo tornou-se uma componente essencial do programa de pesquisa da gramática gerativa, com resultados muito proveitosos, em particular no domínio da teoria sintática. ${ }^{3}$

A nova sintaxe comparativa difere da tradição comparativa clássica quanto ao que se refere ao seu objetivo fundamental que não é histórico, mas psicológico: o objetivo fundamental do programa não dá conta do desenvolvimento das línguas, mas do objeto cognitivo, o conhecimento da língua que os falantes partilham, e a aquisição desse conhecimento. É possível responder à questão fundamental sobre o papel da experiência e

\author{
${ }^{1}$ Agradecemos a \\ observação de Mary \\ Kato sobre esse fato, \\ quando destaca que Ross \\ já levanta essa questão. \\ Destacamos que esse fato \\ pode ser ilustrado na \\ análise de Ross (1967), \\ por exemplo, referente \\ à questão de movimento \\ de preposições \\ desgarradas (stranded), \\ em decorrência da \\ obrigatoriedade ou de \\ restrições impostas por \\ determinadas línguas. \\ ${ }^{2}$ Grande parte dessa \\ discussão sobre a sintaxe \\ de línguas particulares \\ e a sintaxe comparativa \\ reflete uma leitura de \\ Rizzi (1988, 2008), \\ Pollock (1998, 2008), \\ Kayne (2000, 2005) e \\ Kayne \& Cinque (2005). \\ ${ }^{3}$ Cumpre destacar que \\ essa afirmativa de Rizzi \\ refere-se ao ano de 1988.
}


das propriedades intrínsecas na constituição do saber linguístico do falante adulto; será crucial determinar o que pode variar e o que resta invariável entre as línguas. Essa informação somente pode ser obtida através de um estudo comparativo, cf. Rizzi, op. cit., p. 1.

A partir da análise de vários fenômenos, com base na Teoria de Princípios e Parâmetros, Rizzi afirma que "as propriedades observáveis com relação a que línguas podem variar não são autônomas, mas tendem a se organizar em tipos que são bastante estáveis, os tipos linguísticos. Então, nós descobrimos que, se uma língua tem uma propriedade $A$, ela terá também as propriedades B e C, mas não as propriedades D e E. Em alguns casos, a abordagem paramétrica pode explicar por que certas propriedades co-ocorrem", cf. p. 6.

Rizzi destaca que "os valores atribuídos a um parâmetro são as diferenças básicas entre dois sistemas gramaticais. Tais diferenças básicas interagem com a estrutura dedutiva da GU que permanece constante, e com outros parâmetros, uma interação que determina muitas diferenças derivadas. Seguindo o caminho inverso, é possível então encontrar várias diferenças observáveis para uma bifurcação básica, a atribuição de valores diferentes para um mesmo parâmetro", cf. id.ibid.

Rizzi destaca, ainda, que nessa ótica, não é surpreendente que a teoria paramétrica tenha determinado um novo impulso para os estudos da variação, sobretudo no domínio da sintaxe. Ela possibilitou igualmente a esses estudos uma dimensão teórica que teria sido dificilmente previsível até bem recentemente.

A Teoria dos Parâmetros forneceu um instrumento teórico descritivo muito poderoso para o estudo da invariância e da variação da linguagem. Ela ofereceu igualmente um modelo plausível da aquisição da sintaxe: adquirir a capacidade de reunir cadeias de palavras para gerar um conjunto potencialmente infinito de frases comporta (e talvez retorne) a/à fixação de um número limitado de parâmetros binários. Além de oferecer um 
modelo abstrato plausível do modo como a competência do adulto pode ser adquirida, a abordagem paramétrica fornece também ferramentas para compreender como se realiza concretamente o desenvolvimento da linguagem da criança., cf. Rizzi (2008, p. 156).

Kayne (1996, 2000) caracteriza o que ele considera ser uma nova faceta da teoria sintática - a sintaxe comparativa, e nela enfatiza os objetivos da sintaxe microparamétrica. Ele enfatiza a importância dos estudos comparativos sobre a sintaxe das línguas e dialetos, como uma fonte de investigação bastante promissora para fornecer uma ampla compreensão da fixação de parâmetros nessas línguas e dialetos, além de fornecer explicações para a questão das unidades mínimas de variação sintática. Para ele, a sintaxe comparativa pode ser pensada como uma faceta da teoria sintática que se ocupa diretamente da questão de como caracterizar as propriedades das línguas humanas, que não são universais. E o estudo das diferenças entre línguas deve obviamente ocorrer junto ao estudo do que elas têm em comum, isto é, junto ao estudo dos princípios da gramática universal que interagem com os parâmetros das línguas específicas para produzir a variação observada. Similarmente, existem fortes razões para acreditar que procurar os princípios sintáticos universais não pode acontecer sem uma atenção especial à variação sintática.

A propósito da importância quanto à identificação das diferenças entre as línguas, a sintaxe comparativa pressupõe o trabalho com mais de uma língua, mas não é simplesmente isso. Por um lado, espera-se caracterizar e delinear os parâmetros que subjazem às diferenças sintáticas entre as línguas. Por outro lado, espera-se explorar essas diferenças como uma nova fonte de evidência sobre a caracterização e descrição dos princípios da gramática universal (GU), das propriedades que, em virtude da contribuição da (componente sintática da) faculdade de linguagem humana, será encontrada para melhor entender cada língua humana, cf. Kayne (2005, p. 3). 
Vários argumentos apresentados em estudos comparativos realizados sobre várias línguas, aparentadas ou não, a questão da caracterização dos parâmetros, os seus efeitos, os efeitos de diferentes parâmetros ou a "extensão" desses efeitos, assim como o próprio uso do termo "parâmetro" para caracterizar todas as diferenças interlinguísticas, independente do alcance de efeitos associados com algum outro parâmetro são analisadas por Kayne (2005), que argumenta a favor de uma outra dimensão de interesse no universo dos parâmetros que tem a ver com uma dimensão potencial entre microparâmetro e macroparâmetro.

A partir dessa nova dimensão, ele aborda a distinção entre sintaxe microparamétrica e sintaxe macroparamétrica. Para ele, o trabalho em sintaxe microparamétrica fornece um novo tipo de microscópio para investigar os trabalhos em sintaxe. É essa sintaxe, em geral, que está em debate, e não apenas a própria sintaxe comparativa; esse é um ponto que vale a pena enfatizar: o estudo dos princípios da sintaxe não é não pode ser uma iniciativa separada do estudo dos parâmetros.

Para ilustrar essa questão, ele utiliza exemplos do inglês quanto ao uso de whether/if, em 'frases interrogativas infinitivas encaixadas', comparadas a exemplos do francês e do italiano, referentes ao uso de um termo equivalente a if nessas línguas, em frases infinitivas controladas, cf. exemplos (1) - (5).

(1) We don't know where to go.

(2) We don't know whether to leave.

Mas não admite:

(3) * We don't know if to leave.

As línguas românicas admitem interrogativas infinitivas como em inglês, mas elas não têm uma palavra 
que corresponda exatamente a whether, elas utilizam uma contraparte, mais geral, equivalente a if. Algumas línguas românicas têm geralmente um infinitivo controlado com (sua contraparte de) if, por exemplo, o francês:

$(4){ }^{*}$ Jean ne sait pas si partir

Mas, surpreendentemente, algumas línguas românicas admitem isso, por exemplo, o italiano:

(5) Gianni non sa si partire

Para Kayne, uma questão para a sintaxe comparativa seria perguntar a que essas diferenças intraromânicas devem se correlacionar, ou seja, por quê algumas línguas românicas, como o francês, não admitem if + infinitive, enquanto outras o admitem, por exemplo, o italiano. E ele aponta como uma possibilidade de fazer aparecer essas diferenças intra-românicas, verificar, por exemplo, se essas diferenças têm a ver com a colocação

${ }^{4}$ Para mais detalhes sobre essa e outras questões, ver Kayne (2005, p. 4-11).

A constatação de que as línguas românicas que são como o francês, com relação ao exemplo (4) acima, têm a ordem clítico pronominal + infinitivo, enquanto línguas como o italiano, cf. exemplo (5), têm a ordem infinitivo + clítico é por ele identificada. E essa correlação nas línguas românicas entre controle com if e a ordem infinitiveclitic tem importância evidente para uma tentativa de delimitar o(s) parâmetro(s) que subjazem às diferenças sintáticas encontradas. Para ele, esse tipo de correlação deverá ocorrer apenas como o resultado do trabalho em sintaxe comparativa. ${ }^{4}$

Por outro lado, o estudo de (1) - (5) também é relevante para a discussão de microversus macroparâmetro, em especial à ideia de que aparentemente diferenças macroparamétricas podem ser transformadas em conjuntos de microparâmetros (i.e., em 
diferenças produzidas pelos efeitos adicionais de alguns microparâmetros). Essa ideia produziria uma conjetura geral - cada parâmetro é um microparâmetro.

O que isso significaria é que cada parâmetro sintático é semelhante ao que cada um de seus (dois) valores produz (quando todos os outros valores são previsíveis) um par de gramáticas admissíveis (UG) que caracterizam duas línguas que todos nós (informalmente) admitiríamos como estreitamente relacionadas.

A importância de (1) - (5) é demonstrar que microparâmetros (p. ex., aqueles microparâmetros relativamente responsáveis pela ordem clítico-infinitiva versus infinitiva-clítico) são totalmente capazes de participar da explicação de um "conjunto de propriedades" no caso da correlação com controle de cláusulas interrogativas com if.

Kayne levanta várias questões sobre parâmetros sintáticos, inclusive sobre o fato de considerar os elementos funcionais como traços invariáveis dos parâmetros, e várias outras, e conclui parte do seu texto afirmando que a sintaxe comparativa tornou-se indispensável (senão privilegiada) de nossa tentativa de entender a (componente sintática da) faculdade da linguagem humana.

Tendo em vista a importância que tem sido atribuída aos estudos em sintaxe comparativa, especialmente quanto à questão da invariância e da variação sintática de línguas aparentadas ou não, com o aporte da sintaxe gerativa chomskyana, numa perspectiva sincrônica e/ou diacrônica, gostaríamos de ratificar a nossa concordância sobre a importância dos estudos em sintaxe comparativa, enfatizando algumas questões que devem ser priorizadas num programa de investigação na perspectiva acima delimitada:

a) Os valores atribuídos a um parâmetro são as diferenças básicas entre dois sistemas sintáticos, donde a importância de identificar e analisar os parâmetros sintáticos das línguas particulares que interagem com os princípios 
da gramática universal, ou seja, o que as línguas têm em comum, e quais os parâmetros de variação sintática que permitem estabelecer as distinções entre essas línguas;

b) Fornecer explicações sobre a questão das unidades mínimas de variação sintática, e possibilitar explicações satisfatórias sobre a fixação dos parâmetros nessas línguas.

Para concluir, queremos destacar que estudos dessa natureza poderão contribuir para a compreensão do português brasileiro, se considerarmos as grandes influências de outras línguas em nossa língua. Apenas para citar algumas influências no processo de formação da história de nossa língua, cumpre citar: as línguas indígenas, as línguas crioulas de base lexical portuguesa, as línguas africanas, o português europeu, o espanhol, o francês, e várias outras.

Quanto à influência de línguas crioulas de base lexical portuguesa no português brasileiro, queremos fazer referência a algumas análises que têm utilizado uma abordagem descritiva e comparativa, aplicada às línguas crioulas como seria com qualquer língua não crioula. E, nesse sentido, concordamos com Gadelii e Zribi-Hertz (2007) quando afirmam que os trabalhos sobre as línguas crioulas tendem a completar a descrição sincrônica, por uma reflexão diacrônica, sobre a origem possível das formas estudadas.

Nessa perspectiva, cumpre destacar algumas análises sobre as línguas crioulas na perspectiva da sintaxe comparativa, através de uma abordagem comparativas das línguas crioulas com as suas línguas lexificadoras. Algumas desses análise podem ser encontradas em Baptista (2002), Baptista \& Guéron (2007), Gadelii \& Zribi-Hertz (2007), e várias referências aí encontradas. 


\section{Referências}

BAPTISTA, Marlyse. The Syntax of Cape Verdean Creole. Sotavento Varieties. Amsterdam/Philadelphia: John Benjamins Publishing Company, 2002.

BAPTISTA, Marlyse \& GUÉRON, Jacqueline (Eds). Noun Phrases in creole languages. A multi-faceted approach. Amsterdam/ Philadelphia: John Benjamins Publishing Company, 2007.

GADELLI, Karl et ZRIBI-HERTZ, Anne. Grammaires créoles et grammaire comparative. Saint-Denis: PUV, 2007.

GUÉRON, Jacqueline et POLLOCK, Jean-Yves. Grammaire générative et syntaxe comparée. Paris: Éditions du CNRS, 1991.

KAYNE, Richard S. Microparametric Syntax: Some Introductory Remarks. In James R. Black and Virginia Motapanyane. Microparametric Syntax and Dialect Variation. John Benjamins Publishing Co, 1996.

KAYNE, Richard S. Parameters and Universals. New York: Oxford University Press, 2000.

KAYNE, Richard S. Some Notes on Comparative Syntax, with Special Reference to English and French. In Guglielmo Cinque and Richard S. Kayne (Eds). The Oxford Handbook of Comparative Syntax. New York: Oxford University Press, 2005.

POLLOCK, Jean-Yves. Langage et Cognition. Introduction au programme minimaliste de la grammaire générative. Paris: PUF, 1998.

POLLOCK, Jean-Yves. La grammaire générative et le programme minimaliste. In Jean Bricmont et Julie Franck. Chomsky. Paris: Éditions de l' Herne, 2007: 94-119. 
RIZZI, Luigi. A new comparative Syntax: principles and parametrs of universal grammar. Université de Genève, 1988.

RIZZI, Luigi. Une théorie de la syntaxe comparative. Prefácio in: Yves Roberge et Marie-Thérèse Vinet (eds) La variations dialectale em grammaire universelle. Canada: Presses de l' Université de Montréal/ Les Éditions de l' Université de Sherbrooke, 1989.

RIZZI, Luigi. L'acquisition de la langue et la faculté de langage. In Jean Bricmont et Julie Franck. Chomsky. Paris: Éditions de l' Herne, 2007: 147-157. 